\title{
Dar-se como coisa que ouve: afetos de sonoridade na obra Escuto histórias de amor, de Ana Teixeira
}

Daniele Pires de Castro*

\begin{abstract}
RESUMO: Entre os anos de 2005 e 2012, a artista brasileira Ana Teixeira sentou-se em uma cadeira em vias públicas de diferentes cidades com uma cadeira vazia ao seu lado. Uma placa que dizia Escuto histórias de amor convidava os passantes a sentarem-se ao seu lado e falar. Nenhum registro do teor das narrativas foi feito, à artista interessava apenas a escuta. O presente artigo investiga como, ao se concentrar mais no gesto de ouvir que nas histórias contadas, Ana Teixeira propõe um encontro no qual a via de contágio não é a linguagem, que sempre nos convoca à interpretação, mas o som e, portanto, o corpo: seria a carne e não o intelecto a camada de permeabilidade.
\end{abstract}

PALAVRAS-CHAVE: afetos, encontro, escuta

ABSTRACT: Between 2005 and 2012, the brazilian artist Ana Teixeira sat in a chair on streets of different cities with an empty chair beside her. A sign that read I hear love stories invited passersby to sit beside her and talk. No record of the content of the narratives was done, the artist was only interested in listening. This paper aims to investigate how, by focusing more on the act of listening that on the stories told, Ana Teixeira proposes a meeting in which the channel of affection is not the language, that always calls us to interpretation, but the sound and therefore the body: it would be meat and not intellect the permeability layer.

KEYWORDS: affection, meeting, listening

*Daniele Pires de Castro é doutoranda do curso de Pós-Graduação em Comunicação e Cultura da UFRJ e mestra em Comunicação pela UFF. 


\section{Introdução: Por outra ética doação}

De que formas dispomos para nos dar? Seria dar-se a simplicidade de um gesto de afeto, como dar um beijo, um abraço, um afago, dar a mão ou o ombro? Seria dar-se o abrir mão de um pouco de si, como dar o sangue, uma parte do próprio corpo, do tempo, da energia? Seria dar-se somente o gesto radical de entregar toda a vida? Em nossa cultura, moldada pela moral cristã, o gesto maior de doação é aquele desinteressado, sendo sua figura mais radical Cristo que entregou sua própria vida em nome de seu amor à humanidade. Nesse sentido, sugiro aqui, a doação é considerada ainda mais admirável quando se trata de uma total abnegação de si mesmo ou de algo que se possui, sem que jamais seja possível restituir: entregar a própria vida, doar o corpo que uma vez destituído de uma parte de si não se poderá reconstituir, abrir mão do tempo e da energia que uma vez despendidos não serão recompostos.

Contra essa ideia cristã de uma doação de mão única — alguém que dá e alguém que recebe —, o filósofo Mario Perniola recupera o verbo do grego antigo déchomai, que parece veicular uma duplicidade de significados: possui ao mesmo tempo a acepção de dar e de tomar. O verbo quer dizer aceitar, receber, acolher, mas também tomar na acepção de atrair e possuir (PERNIOLA, 2005, p. 129). Ao utilizar este termo não se distingue os polos opostos de doador, como a figura ativa desta dupla, e receptor, como a figura passiva, ambas são também tomadoras, guiadas por uma vontade de pegar algo do outro no domínio de um desejo de atrair e ser atraído em uma condição de mútua disponibilidade. Entendo que Perniola propõe, assim, uma nova ética da doação, fundamentada em uma dimensão de reciprocidade que se afasta do pressuposto que afirma o dar como uma pré-condição do receber. Enquanto este opera dentro de uma lógica da recompensa, a proposta de Perniola estimula o que seria uma coincidência de disponibilidade.

Ao operar por meio da recusa da distinção entre os polos opositores de doador e receptor/tomador, o filósofo rompe com outras concepções duais próprias ao modo de pensar ocidental, entre elas, a oposição entre sujeito e objeto. É a partir desta recusa que ele erigirá a noção, fundamental para sua obra, de "coisa que sente", como uma maneira de superar a relação de uso que tradicionalmente se estabelece entre entes que se colocam um diante do outro mesmo que por vezes de maneira alternada - como manipulador e manipulado, condutor e conduzido, conhecedor e desvendado, construtor e construto, entre tantas outras, seguindo 
o modelo típico ao cotidiano da sociedade contemporânea, no qual se procura sempre distinguir os polos ativos e passivos de uma ação. Assim, em um mundo habitado por relações de uso que caucionam e são caucionadas pelas figuras do sujeito e do objeto, Mario Perniola propõe a noção alternativa de coisa, que substitui a instrumentalidade característica da relação daquela dupla de opostos por uma relação baseada na dimensão sensível dos corpos. Concomitantemente, apresenta outra proposta de ação avessa à utilidade: no lugar daquela que visa a atingir um objetivo específico, o filósofo propõe o agir sem metas, a relação entre coisas que se abre ao totalmente imprevisível, ao aqui e agora da sensação. Assim, também corresponde ao ato de dar-se como coisa que sente, uma nova configuração temporal que privilegia o presente no lugar de um tempo que corre sobre uma linha progressiva.

Assumindo uma perspectiva baseada nesses escritos de Mario Perniola, define-se então outra noção do gesto de doação: não a ideia de um mero dar-se, que mesmo a princípio desinteressado, aguarda uma futura recompensa, conforme a moral cristã, mas de um dar-tomar-receber recíproco que se dá na mutualidade da experiência sensível entre coisas que sentem no momento presente. Trata-se de um esforço em identificar maneiras pelas quais o gesto de dar-se pode ser fruto da disponibilidade à diferença ${ }^{1}$, inaugurando outra ética da relação.

Perniola ressalta o papel da arte nesse processo. Ele identifica como, na atualidade, é possível perceber um movimento de corrosão do caráter espacial da obra que dissolve sua identidade e organicidade (PERNIOLA, 2005, p. 113). Ele destaca a potência das instalações como entidades inorgânicas não utilitárias, obras que transbordam fora de si mesmas e adquirem uma externalidade radical e extrema (PERNIOLA, 2005, p. 116). Nesse sentido, acrescenta:

as instalações não devem ser consideradas como o objeto da avaliação de um visitante; a relação com este último é completamente invertida quanto à tradicional visita a museus e galerias. É a instalação que sente o visitante, que o acolhe, o tateia, o apalpa, dirige-se a ele, faz com que ele nela mesma, o penetra, o possui, o inunda. Não se vai às mostras para ver e desfrutar da arte, mas para ser vistos e possuídos pela arte (PERNIOLA, 2005, p. 117)

Neste artigo, pretendo detectar o gesto de dar-se, em um ato simples e cotidiano, afinal, sendo um afeto que emerge de um encontro de mútua disponibilidade e contágio, não é preciso recorrer a grandes acontecimentos, basta que os corpos estejam imbuídos de um mesmo caráter. Trata-se do ato de contar e ouvir histórias, tomando como objeto a intervenção realizada 
pela artista Ana Teixeira em várias cidades do mundo intitulada Escuto histórias de amor. Pensando a partir das definições propostas por Perniola, a intervenção de Ana pode ser vista como instalação. Não é uma obra que está ali para ser vista, sentida, utilizada ou avaliada pelo visitante, mas para qual ele deve permitir-se ser acolhido, restituindo o encontro com a artista/ obra em sua dimensão sensível na qual, não se trata de sentir e pensar, mas viver a arte.

\section{A escuta como gesto}

Entre os anos de 2005 e 2012, Ana Teixeira sentou-se em uma cadeira em parques, praças e vias públicas de diferentes cidades do mundo com uma cadeira vazia ao seu lado. Enquanto tecia uma mesma peça de tricô vermelho, uma placa que dizia "Escuto histórias de amor", escrito no idioma do país visitado, convidava os passantes a sentarem-se ao seu lado e falar. Nenhum registro do teor das narrativas foi feito, a documentação existente dessas intervenções são filmagens que capturaram de longe a imagem daqueles que pararam e se sentaram para contar histórias a Ana, mas o som que acompanha é o das ruas, ruídos e barulhos do trânsito de carros e pessoas que povoam a cidade. À artista não interessava criar uma coleção de belas histórias, tomar ensinamentos, compreender a verdade sobre o amor ou mesmo mapear a experiência de tal sentimento pelo mundo, interessava-lhe apenas o gesto de escutar.

Por mais que pareça inquestionável, dentro nos nossos atuais padrões de comportamento, que uma ação é sempre iniciada em vias de atingir uma meta, esta não é a única forma. Aqui, vale elucidar as concepções de Georgio Agamben sobre a ação: haveria três tipos, o agir, o fazer e o gesto. Enquanto o fazer é um meio destinado a um fim, o agir é o fim em si mesmo, ou seja, uma finalidade sem meios. Já o gesto é um terceiro gênero de ação que rompe com "a falsa alternativa entre fins e meios" (AGAMBEN, 2008, p. 13): é a exibição de uma medialidade pura, o tornar visível um meio como tal (AGAMBEN, 2008, p. 13). Estamos constantemente variando entre o fazer e agir sem abertura para o novo que emerge do gesto, sem destituir a ação de sua usual relação com a finalidade. O que Ana expõe em seu trabalho é a pura medialidade do gesto. Ao não subordiná-lo a uma finalidade específica, quer dizer, ao não fazer de sua escuta um meio de coleta de material ou uma atividade de pesquisa, a artista nega essa lógica instrumental.

Para que servem as palavras que ouço? Que destino posso dar a tais belas narrativas? Se pautasse suas intervenções por tais parâmetros instrumentalizadores, Ana acabaria tendo que 

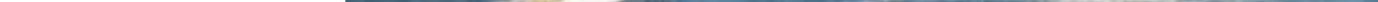
hierarquizar as histórias que Ihe foram contadas, teria que criar padrões de avaliação e classificação, teria que interpretá-las e identificar nelas os trechos mais valiosos. No entanto, no evento proposto pela artista, não cabe o sujeito Ana que distingue, julga e escolhe, cabe apenas o dar-se como coisa que escuta. Em diversas entrevistas sobre o trabalho, a artista afirma que se sua intenção não era registrar as histórias, também não era necessariamente entendê-las. Ela conta que não compreendia francês ou alemão, no entanto, realizou a ação na França e na Alemanha, pois a escuta e não a narrativa era o mais importante. A via de contágio proposta, portanto, não era da linguagem, que sempre nos convoca à interpretação, mas a da voz, do som, do corpo: seria a carne e não o intelecto a camada de permeabilidade desse encontro.

Assim, Escuto histórias de amor elabora de maneira sutil e poética uma crítica à concepção específica da ação que vigora no interior da nossa atual cultura da gestão de si e que por vezes também aparece na arte dita interativa. Tal concepção manifesta a noção de um sujeito sempre em busca da satisfação de seus desejos e objetivos particulares através de ações que são uma mera produção de prazeres e recompensas. Ao contrário, conforme citado anteriormente, Mario Perniola propõe uma experiência deslocada, descentrada, livre da intenção de atingir um objetivo (PERNIOLA, 2005, p.22), o que permitiria a abertura de outra temporalidade: não um tempo progressivo que corre a uma apoteose final, mas um tempo em suspensão de pura disponibilidade dos corpos ao sentir. Nesse sentido, compreende-se aqui que a proposta de Ana Teixeira ao escutar as histórias sem fazer delas objetos de interpretação ou arquivo pode ser vista como uma forma de recuperar o gesto no interior da ação, de trazer à tona a pura medialidade dos corpos em detrimento do objetivo. Há, nessa obra, uma mudança de postura em relação à ação, uma maneira de resistir às pressões de uma cultura que nos impele à produção de um si mesmo autônomo, que instrumentaliza ações e relações em prol de pequenos ou grandes projetos e gozos. O que a artista propõe, em contrapartida, é fazer bastar a transição, o fluxo, o processo, o meio, no lugar do finalizar, conseguir, terminar, concluir.

\section{O tempo como duração}

O gesto de Ana Teixeira é uma aventura, tanto para a ela quanto para o outro. Não que lhe tenham acontecidos fatos dignos de uma cena de filme de ação ou de uma notícia no jornal televisivo, os imprevistos são sutis aos olhos de uma cultura do espetáculo. É um olhar, um 
toque, uma brisa, uma voz, ou até a ausência. Ana conta que em Veneza - curiosamente, a cidade dos amantes - ninguém se sentou para contar uma história. Foi a aventura da espera, mas que ainda assim constrói tessituras: a narrativa de amor de Ana é o emaranhado das histórias que escutou dos outros, mas também dos momentos em que aguardava sentindo a cidade, suspensa no tempo sem estar passiva. Ouvir e esperar são gestos que advém da pausa, que não mobilizam um fazer, mas um sentir, na contramão de um tempo cotidiano que quer nos lançar o tempo todo à frente. Nesse sentido, o gesto proposto pela artista engendra uma nova experiência temporal. Ao sentar-se ao lado de Ana Teixeira para contar uma história, o passante realiza uma quebra em seu trânsito, fazendo da rua não mais um corredor de passagem, mas um espaço próprio à emergência do evento. Assim, arrisca-se na recusa da experiência do tempo progressivo da vida citadina em prol de outra experiência temporal que se constrói na relação entre o contador da história e a ouvinte.

O gesto de tecer, inspirado, segundo a própria artista, na figura de Penélope a espera do regresso de Ulisses, explora a dimensão de um tempo contraído, que não se esgota. A esposa fiel aguarda o retorno de seu marido em um tempo que retém o passado, a presença de Ulisses a seu lado, e antecipa o futuro, o seu retorno a casa. Para que a espera seja possível, é preciso que o tempo não passe. Para os pretendentes de Penélope o tempo continua a progredir, por isso ela cria sua artimanha e toda noite precisa desfazer sua tessitura e retornar ao ponto inicial, criando um ciclo aparentemente interminável de transformação, de construção e desconstrução, sob uma aparência de imobilidade. O tempo não passa, não progride, mas muda continuamente, tornando-se duração. Ana Teixeira aguarda como Penélope, mas não precisa desfazer seu cachecol. Sua coreografia da tessitura não tem um lugar aonde chegar, pode ser infinita. E assim é: a cada espera, em cada lugar, a feitura do mesmo cachecol vermeIho é recomeçada, um costurar que entrelaça histórias ouvidas e espaços ocupados. O tempo da oralidade desperta assim uma dimensão de presença do acontecimento, porém transporta também para o tempo da espera e do recomeço. A cada volta um novo evento que não é, nem continuação do anterior, nem o predecessor de um próximo, é repetição e diferença. É o tempo infinito, em ciclos que a cada volta adicionam uma nova trama ao tecido de narrativas, sem cortes ou finalizações, apenas acumulação. 


\section{O som como espaço}

Ana Teixeira define sua obra como uma ação, mas a experiência proporcionada por ela difere da daquelas mais típicas de algumas performances, dos happenings e dos atuais flash mobs. Nestes, há uma experiência precária do instante vivido, a evidencia da inevitável passagem do tempo. São capturas, instantâneos, enquanto o tempo da espera e da escuta é aquele da persistência. Trata-se, na obra de Ana, de uma ação que é menos a promoção de um acontecimento no tempo que progride e mais uma ocupação do espaço, uma maneira de penetrar a cidade convidando o outro a desfrutar desta mesma disponibilidade. Cada evento é uma comunhão indiscernível entre duração e lugar: o espaço não é um plano de fundo para o encontro, é seu constituinte. Nesse sentido, há um deslocamento da história contada (da compreensão da narrativa de um sujeito) para o evento da contação da história (o estar no espaço como espera e encontro).

Segundo Mario Perniola, o favorecimento da dimensão da espacialidade em desfavor da temporalidade opera um afastamento do horizonte conceitual caracterizado pelo chamamento à interioridade, à consciência, ao sujeito, em direção à disponibilidade ao exterior e ao neutro (PERNIOLA, 2005, p. 81). O filósofo faz menção à dimensão sonora da música, que colocada em primeiro plano, afasta tanto a concepção sentimental, que a vê como expressão de uma interioridade emocional, e a da vitalista, que a vê como a manifestação espontânea da existência natural. O som, percebido em sua neutralidade e indiferente inorganicidade, afirma, é a essência da música (PERNIOLA, 2005, p. 78). Ele cria um campo de atração permanente entre os corpos, funcionando como um ímã. Ao privilegiar a escuta e não a narrativa, Ana Teixeira parece pretender resgatar tal dimensão espacial da fala como som em detrimento da dimensão temporal da fala como linguagem. Porém, a percepção da dimensão sonora da fala é constantemente ameaçada por seu papel como significante, que a conecta fortemente à existência do significado. Assim, a própria Ana admite ser difícil desmotivar os contadores a serem entendidos. Nos países onde não falava a língua, como na França ou Alemanha, as pessoas contavam suas histórias em inglês para serem compreendidas. Ainda assim, Ana Teixeira não cessa de ressaltar que o que lhe interessa não são as histórias, cuja valorização induziria ao centramento na experiência passada individual, mas provocar fissuras no cotidiano. Esse desinteresse da artista pelo indivíduo é também percebido por aqueles que se sentam junto à Ana, como compreende, uma mulher, explicando porque confiou a Ana uma história 


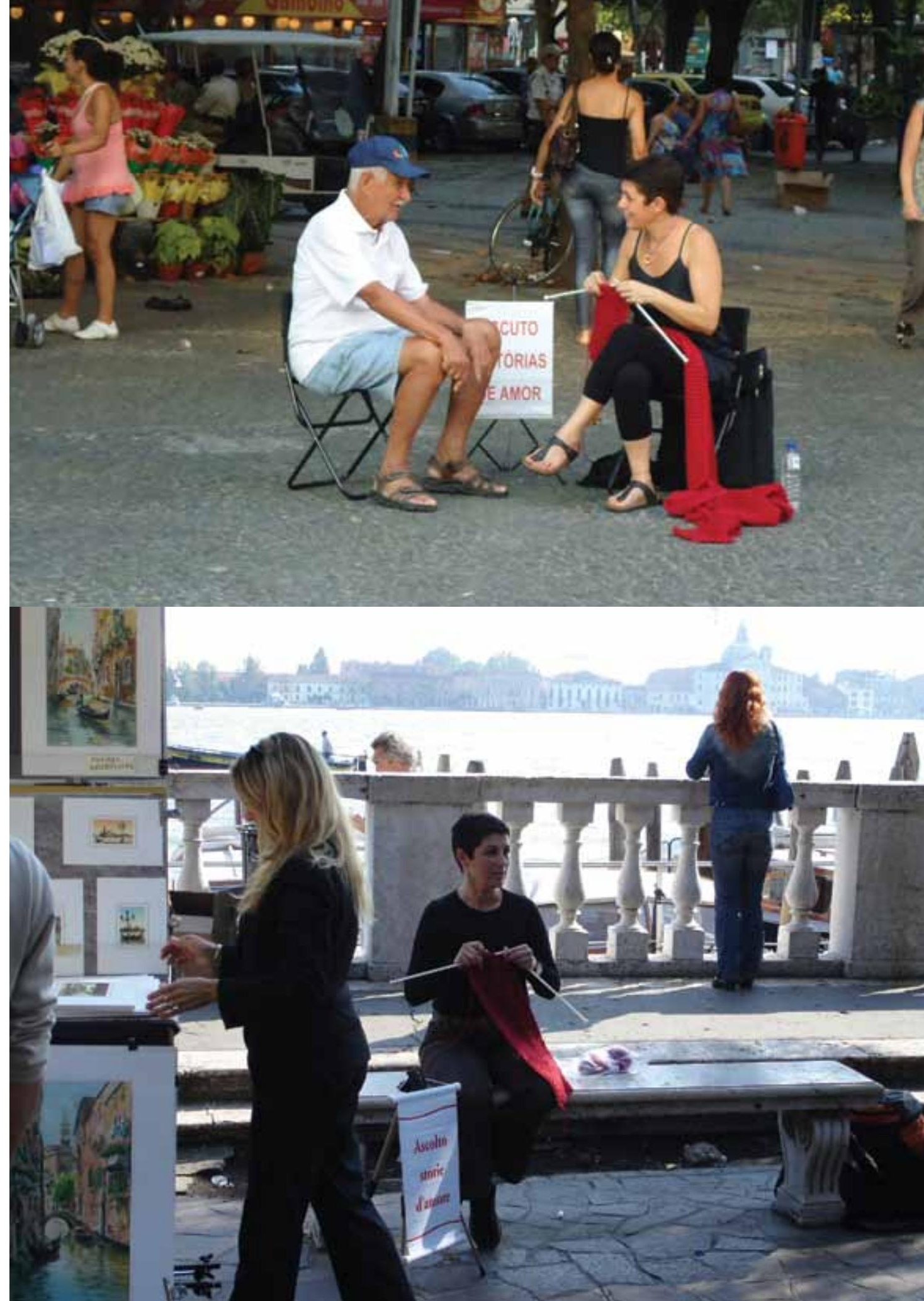


de amor: "Ela não tava estava interessada na minha vida", disse uma das contadoras em uma reportagem do Jornal da Cultura.

Assim, é possível compreender a ação aqui estudada como uma experiência contemporânea do espaço tal qual definida por Mario Perniola: aquela que se configura sobre um modelo dinâmico que lança o sujeito para fora de si. (PERNIOLA, 2005, p. 95) Ao ouvir histórias de amor sem julgá-las, coletá-las, ou mesmo tentar compreendê-las, Ana se lança para fora de si, em uma experiência espacial que convoca o outro a fissurar o espaço da cidade e penetrá-lo junto com ela. A ação rompe também com a tradicional concepção que opõe o espaço privado como lugar da experiência íntima do sujeito ao espaço público como lugar da sociabilidade. A aventura do amor, normalmente confinada à interioridade da casa e da vivência subjetiva, é convidada a sair do espaço da intimidade para se tonar a via de acesso a um estranho e de uma nova experiência na cidade. O que não quer dizer que se trate apenas de um choque de opostos. Por não estar interessada "na vida" do contador da história, como afirmou uma das participantes entrevistas, a obra incentiva aqueles que sentam ao lado de Ana a ter outra experiência de individualidade, na qual não estão ali na condição de sujeitos expondo sua intimidade em um espaço "inadequado", mas na condição de coisa que sente em um encontro com outra coisa que sente, em um evento de doação de mútua disponibilidade.

\section{Dar-se como coisa que ouve}

Segundo Mario Perniola, o mundo das coisas - corpos, sons e pensamentos - é dotado de uma generosa e hospitaleira espacialidade que infinitamente nos acolhe com sua disponibilidade imediata (PERNIOLA, 2005, p. 82). Ampliando essa noção de disponibilidade recíproca da coisa que sente, é possível incorporar as dimensões do afeto e do contágio, trazendo a contribuição de outros autores que também procuram pensar o encontro e a relação fora de um ponto de vista instrumentalizante. Para isso, em primeiro lugar, recorro a Nietzsche, cuja filosofia perspectivista ajudará a situar a questão em torno dos conceitos de sujeito, objeto e coisa.

O perspectivismo nega "toda instância transcendente ou subjacente ao mundo" (ROCHA, 2003, p. 17), que é considerado "uma diversidade caótica em constante fluxo, um processo destituído de finalidade, uma multiplicidade de forças sem qualquer unidade, um puro devir que jamais atingirá um estado de ser" (ROCHA, 2003, p. 17), ou seja, algo que não é inteligível. 
O perspectivismo se afasta do relativismo porque nega a possibilidade de um ponto de vista externo: o homem só poderia ser o sujeito e o mundo só poderia ser o objeto de seu olhar, se houvesse distinção entre os dois, "mas o homem não é exterior ao mundo" (ROCHA, 2003, p.33). Não há, portanto, objetividade ou a "coisa em si", bem como não há um sujeito metafísico. Desta maneira, Nietzsche nega também a unidade do eu, que não é mais que "a ficção de um ser imune ao movimento do devir, a ilusão de uma substância que permanece inalterada por trás da flutuação dos afetos e da variação de perspectivas" (ROCHA, 2003, p. 21).

Assim, de acordo com Silvia Rocha, Nietzsche lança as bases do "relacionismo", que é a constatação de que, na ausência, de um ponto de vista que seja transcendente, tudo o que há são as relações (ROCHA, 2003, p.162). As coisas são, portanto, constituídas a partir da sua relação com outras coisas, não existindo a priori. O resultado é que sujeito e objeto não são tomados como coisas independentes, mas um é produzido pelo outro. O sujeito atravessado pelo perspectivismo não é aquele capaz de mudar de posição, mas aquele que, longe de ser constituído por uma essência, é capaz de "tornar-se outro".

O perspectivismo implica o abandono do conceito de sujeito e da ideia de substância. Não há um eu que ocupa, sucessivamente, diferentes perspectivas (e que portanto, permaneceria imutável por trás dessa mudança ou idêntico por trás das relações) [...] O outro não reside portanto no exterior do sujeito, como uma instância que o afeta de fora, mas é indissociável daquilo que o homem, a cada momento, se torna. Somos sempre um outro, não apenas porque nos transformamos no tempo, mas porque aquilo que nos constitui é indissociável das circunstâncias que encontramos. (ROCHA, 2003, p. 167)

O relacionismo nietzschiano parece inspirar diversos autores contemporâneos, que pensam, em diferentes gradações, um sujeito e consequentemente um objeto que não são mais unidades pré-constituídas, mas entes em contínua transformação. Como uma forma de fugir da dicotomia, outros termos são introduzidos, como faz Mario Perniola ao referir-se à "coisa". Seja qual for o caminho tomado, as pesquisas apontam em uma mesma direção: a possibilidade de pensar a dimensão de contágio da relação entre as "coisas" que as tornam entes em contínua transformação. Tendo apresentado a perspectiva filosófica da qual emerge esta fala, recorreremos a autores que parecem partir desses mesmos pressupostos para pensar a arte, como caminho para compreender a dimensão da porosidade do corpo como coisa na obra de Ana Teixeira. 
Em primeiro lugar, para pensar uma possível vulnerabilidade do corpo e seu estatuto de coisa é preciso abandonar a noção de unidade orgânica como partes que se conectam em um todo funcional e que faz dele uma estrutura acabada e imune a atravessamentos. Para tal, contribui a análise do trabalho de Francis Bacon, operada por Gilles Deleuze, que propõe uma diferenciação entre rosto e cabeça, que aqui ousaremos traçar uma equivalência entre narração e ouvido para pensar o trabalho de Ana.

O rosto institui princípio de reconhecimento. Permanecendo dentro da lógica do figurativo, são imagens criadas a partir de uma perspectiva representacional sujeita a processos de identificação e organização. Já a cabeça é, segundo o filósofo, vianda, carne separada de sua estrutura orgânica. Assim, enquanto o rosto é uma "organização espacial estruturada que recobre a cabeça", a cabeça é uma parte do corpo (DELEUZE, 2007, p. 28). Paralelamente a uma distinção entre rosto e cabeça, Deleuze opõe figurativo e figural. O primeiro é a representação, "a relação entre uma imagem e o objeto que ela deve ilustrar, mas implica também a relação de uma imagem com outras imagens em um conjunto composto que dá a cada um o seu objeto" (DELEUZE, 2007, p. 12). Nesse sentido, afirma o filósofo, a narrativa é o correlato da ilustração. Para romper com a representação seria necessário também romper com a narração e impedir a ilustração (DELEUZE, 2007, p. 12). O rosto, poderíamos afirmar, seria a ilustração de um sujeito, sua representação, que, em conjunto e em relação com outras imagens é capaz de contar uma história sobre aquela imagem que é seu protagonista. A cabeça é o que resta após esse rosto ser escovado, levando com ele qualquer ilustração ou narrativa.

O ouvido, no trabalho de Ana, pretende também deixar de ser um órgão particular dentro de um todo funcional, ou seja, menos a porta de entrada de estímulos que depois serão entendidos, interpretados, analisados, identificados ou reconhecidos por uma mente autoconsciente, e mais puro orifício, passagem de afetos de um corpo que sente. O ouvido é o buraco em uma cabeça e não o órgão sensorial de um rosto. É verdade que Ana Teixeira não rompe com a narrativa, mas concentra seu trabalho no gesto de contar e escutar mais do que na própria história contada. Na instalação, apresentada em galerias, que seguiu a ação de rua, o que restou não foram os rostos e suas histórias, mas os corpos e seus encontros. Se buscar o figural é, segundo Deleuze, interromper a narração para ater-se ao fato (DELEUZE, 2007, p. 12), nada mais adequado que deixar muda toda a narrativa para evidenciar o gesto de contar e o de ouvir. Trata-se aqui de ser atravessado pelo que viu e ouviu em uma condição de fragilidade que mantém o corpo/carne/vianda permeável. 
Ser coisa requer o abandono da condição de sujeito que analisa, interpreta, avalia e usa. No lugar de uma relação que assume o outro como um objeto, a noção de coisa permite a instauração de uma imprevisível experiência de encontro, pois não está atada às amarras da instrumentalização. Dar-se como coisa é, portanto, um gesto que é pura medialidade e não uma ação que prevê um resultado ou uma recompensa. Nesse sentido abole a lógica do dar e receber como atividades conectadas por uma relação de causa e efeito em favor de uma indiferenciação entre as duas posturas.

\section{Conclusão: Por um corpo mais poroso}

Ao escutar histórias de amor, Ana Teixeira se dá como coisa que ouve. Narrativas que partem de lugar nenhum e vão para nenhum lugar, que permanecem anônimas, dispersas no espaço da cidade, ininteligíveis sob o barulho da rua. Ana é coisa, assim como aqueles que se sentam juntos a ela em uma condição de disponibilidade que se torna mútua. Ao contar histórias de amor, o visitante se dá como coisa que fala para um estranho. Nesta relação, identidade e biografia são irrelevantes, importantes são o encontro, o evento e sua duração que causam uma fissura na progressão do tempo. Sentar-se para contar uma história a um estranho por motivo nenhum no meio de um dia qualquer é suspender o andamento da vida cotidiana, é desviar-se da eficácia e da produtividade que apontam sempre para frente e para mais.

Ana afirma que sua intenção com as ações é causar uma fissura no cotidiano das pessoas, porém, ela provoca também uma disrupção na relação do indivíduo com sua própria narrativa. Se por um lado, a história de amor apela ao sujeito, à biografia, ao sentimento e ao desejo de construção da experiência amorosa como uma narrativa², por outro lado, a conjuntura proposta por Ana (o fato de ela ser uma estranha, de estar no espaço da rua, de não haver registro e publicização das histórias) desloca a centralidade da ação do sujeito para o evento. É um procedimento que vai na contramão das práticas mais comuns aos nossos dias, relacionadas ao uso das mídias sociais, que incentivam um tipo de construção identitária que faz excessivo uso da imagem fotográfica (que é rosto e não cabeça) e da narrativa de si (através da disposição dessas imagens e textos em linhas temporais progressivas). É a construção de um eu que se conta, e mais do que isso, que torna pública sua própria narrativa. Relacionar a discussão das identidades fabricadas midiaticamente ao "Escuto histórias de amor" poderia ser tema para outro ensaio, o que pretendia indicar rapidamente aqui é que esta obra, apesar de 
também recorrer à narrativa pessoal, desconfigura todo um aparato que faria desse recurso um dispositivo de construção subjetiva típico da contemporaneidade. A narração como evento opõe-se a narrativa construída por imagens e textos planejados: nesta, só cabe pensar o sujeito a partir de uma noção de identidade, enquanto aquela convoca a um abandono de tais categorias e a opção por outras - coisa em vez de sujeito, carne e vianda em vez de corpo, atravessamentos e contágios em vez de identidade e imagem.

O corpo de quem ouve e o corpo de quem conta passam, portanto, por transformações: afastam-se de sua condição de imagem de identificação individual, ou seja, apaga-se o rosto para ficar a cabeça; e abandonam sua condição de estrutura orgânica com unidades funcionais conectadas e assumem seu estatuto de carne, no qual o ouvido e boca não são órgãos, mas canais de atravessamento. Destituídos, assim, de intenção em relação à narrativa, seja de registro, de publicidade, de avaliação ou de uso, o corpo que se dá como coisa que ouve e que fala, torna-se por fim poroso e vulnerável.

Artigo recebido em maio de 2015, aprovado em junho de 2015 e publicado em julho de 2015.

\section{Notas}

1 Vale aqui salientar que tal elogio à diferença em nada se assemelha a uma evocação da tolerância. Esta mantém os diferentes em condição de não contágio, apenas de um suportar-se, de um conviver. Nesse sentido é que a filosofia da diferença funda outra ética do encontro pautada, claro, não em processos de identificação e não identificação, mas de atravessamentos.

2 Supondo-se que provavelmente a maioria dos participantes tenha contado histórias relativas à suas próprias experiências amorosas, apesar de Ana não ter divulgado nenhuma estatística sobre isso.

\section{Referências}

AGAMBEN, Giorgio. Notas sobre o gesto. Revista Artefilosofia. Ouro Preto, n. 4, p. 9-14, jan. 2008.

DELEUZE, Gilles. Francis Bacon: lógica da sensação. Rio de Janeiro: Jorge Zahar Ed, 2007.

PERNIOLA, Mario. O sex appeal do inorgânico. São Paulo: Studio Nobel, 2005.

ROCHA, Silvia. Os abismos da suspeita: Nietzsche e o perspectivismo. Rio de Janeiro: Relume

Dumará, 2003

SIBILIA, Paula. A técnica contra o acaso: os corpos inter-hiperativos da contemporaneidade. Revista Famecos. Porto Alegre, v. 18, n. 3, p. 638-656, set./dez. 2011

\section{Outras referências:}

http://www.anateixeira.com/portal/home-img-search.php?ano=31 